\title{
Determination of neutron flux parameters in PUSPATI TRIGA Mark II Research Reactor, Malaysia
}

\author{
I. A. Alnour $\cdot$ H. Wagiran $\cdot$ N. Ibrahim $\cdot$ \\ S. Hamzah $\cdot$ B. S. Wee $\cdot$ M. S. Elias • \\ J. A. Karim
}

Received: 23 September 2012/Published online: 18 December 2012 (C) Akadémiai Kiadó, Budapest, Hungary 2012

\begin{abstract}
In standardization NAA, it is necessary to characterize the neutron spectrum parameters such as epithermal neutron flux shape factor $(\alpha)$, thermal to epithermal neutron flux ratio $(f)$, thermal neutron flux $\left(\varphi_{\text {th }}\right)$ and epithermal neutron flux $\left(\varphi_{\text {epi }}\right)$ in the irradiation facility to determine the concentration of an element in the sample using absolute and $k_{0}$ standardization methods. The $\alpha$ and $f$ were determined using Cd-ratio multi monitor method using experimental data obtained in PUSPATI TRIGA Mark II research reactor at four irradiation positions $(10,20,30$ and 40$)$ of the rotary rack. The calculated values of $\alpha$ and $f$ ranged from 0.006 to 0.0281 and 18.56 to 19.12 respectively. The average values of $\varphi_{\mathrm{th}}$ and $\varphi_{\mathrm{epi}}$ were found as $2.33 \times 10^{12}$ and $1.23 \times 10^{11} \mathrm{n} \mathrm{cm}^{-2} \mathrm{~s}^{-1}$ respectively. Moreover, a comparison of the neutron flux parameters in the present study shows an acceptable level of consistency with those of previous studies.
\end{abstract}

I. A. Alnour · H. Wagiran

Department of Physics, Faculty of Science, Universiti Teknologi

Malaysia, 81310UTM Skudai, Johor, Malaysia

\section{A. Alnour ( $\square)$}

Department of Physics, Faculty of Pure and Applied Science, International University of Africa, 12223 Khartoum, Sudan e-mail: aaibrahim3@live.utm.my; ibrahim.elnour@yahoo.com

\section{N. Ibrahim}

Faculty of Defence Science and Technology,

National Defence University of Malaysia, Kem Sungai Besi,

57000 Kuala Lumpur, Malaysia

S. Hamzah · B. S. Wee · M. S. Elias · J. A. Karim Malaysia Nuclear Agency (NM), Bangi, 43000 Kajang, Selangor D.E, Malaysia
Keywords Neutron flux parameters - Absolute method . PUSPATI TRIGA Mark II research reactor

\section{Introduction}

The PUSPATI TRIGA (training research and isotope: production by general atomic) Mark II reactor is the only nuclear research reactor in Malaysia. It is a pool type reactor whereby the reactor core is immersed in an open water-pool $2 \mathrm{~m}$ in diameter and $6.3 \mathrm{~m}$ deep and lined with aluminium. It is fueled with enriched ${ }^{235} \mathrm{U}(20 \%)$ combined with zirconium hydride $(\mathrm{U}-\mathrm{ZrH})$ [1-4]. Light water in the reactor tank is used as cooling agent. The reactor uses a two-loop cooling system (primary and secondary) for heat rejection. The primary coolant system consists of three pumps, a heat exchanger, temperature probes, a N-16 diffuser and associated valves and piping. The primary coolant is demineralised using Amberlite resin and is passed to reactor pool where it gets into contact with fuel elements and other metals parts. The secondary coolant system consists of secondary side (shell side) of the heat exchanger, three secondary pumps, two cooling towers, as well as flow meters and water temperature probes [5]. The reactor has a $2.5 \mathrm{~m}$ thick concrete wall to attenuate radiation and act as a shield from contamination. PUSPATI TRIGA Mark II is currently operated with thermal power capacity of $1 \mathrm{MW}$ and has an average neutron flux $1-2 \times 10^{12} \mathrm{n} \mathrm{cm}^{-2} \mathrm{~s}^{-1}$ at the rotary rack and maximum neutron flux reached $1 \times 10^{13} \mathrm{n} \mathrm{cm}^{-2} \mathrm{~s}^{-1}$ at central thimble [2]. It produces neutron with energies ranging up to $10 \mathrm{MeV}$, mainly for neutron activation analysis (NAA) and other applications. A rotary rack (RR) is located at the top portion of the core inside the reflector, and contains 40 irradiation positions as shown schematically in Fig. 1. 